\title{
SISTEMA DE ARRECADAÇĀO E DISTRIBUIÇÃO DE DIREITOS AUTORAIS NOS SETORES TEATRAL E MUSICAL
}

\author{
José D'Amico Bauab \\ Aluno de Mestrado dos Cursos de Pós-Graduação, Área de Direito Civil, \\ sob a orientação do Professor Doutor Carlos Alberto Bittar
}

\begin{abstract}
Resumo: A utilização econômica de uma obra teatral ou musical faz nascer o correspondente direito patrimonial para o seu criador. Este direito é quantificado, arrecadado e, depois, distribuído pelas sociedades a que o autor está filiado. A estrutura e o funcionamento delas advêm das sociedades seculares existentes na França. Entrementes, a eficiência do sistema varia da área teatral para a musical.
\end{abstract}

\begin{abstract}
The economic use of a theatrical or musical work makes appear the corresponding patrimonial right for its creator. This kind of right is calculated, collected and, later, distributed by the societies that the creator is connected with. Their structure and operation result from the secular societies established in France. However, the efficiency of the system changes from the theatrical sector to the musical one.
\end{abstract}

Unitermos:Sistema de "pequeno direito"; Sistema de "grande direito"; Contrato de Representação; Créditos Retidos; Usuário de Direito Autoral.

\section{I - INTRODUÇĀO}

Plasmada no mundo fático, a obra torna-se possível de ser utilizada. Esta utilização pode se verificar pelo próprio autor ou por terceiro (uma empresa do setor, instituição ou órgão do Estado).

Das utilizaçōes econômicas decorrem os direitos patrimoniais que se quantificam em numerário. Surgem, então, dois sistemas básicos para a utilização da obra e a ulterior percepção dos rendimentos correspondentes:

- o institucional, em que existem mecanismos oficiais de autorização, de arrecadação e de distribuição de direitos;

- o contratual, em que as partes definem em cada situação as condições do uso e a sua renumeração. 
O sistema institucional bifurca-se nos:

- sistema do chamado "pequeno direito" - atinente à execução pública de músicas;

- sistema do denominado "grande direito" - referente à representação de obras dramáticas e dramático-musicais.

Ao longo dos anos, foram surgindo inúmeras entidades, ou associações, a fim de proceder a salvaguarda dos direitos autorais de cada categoria: a S.B.A.T. (Sociedade Brasileira de Autores Teatrais), a A.S.A. (Associação de Autores), a S.A.B.E.M. (Sociedade de Autores Brasileiros e Escritores de Música), a A.M.A.R. (Associaçāo de Músicos e Arranjadores e Regentes), a A.S.S.I.M. (Associaçāo dos Intérpretes e Músicos) e outras tantas.

Todas elas, porém, apresentavam pontos comuns entre si como:

a) a necessidade de autorização para quem quisesse utilizar a obra mediante ato da associação;

b) a percepção de direitos pelas entidades e sua subseqüente distribuição aos associados;

c) a possibilidade de defesa dos direitos do autor pelas próprias entidades (sem prejuízo de ação pessoal do titular);

d) a cobrança de taxa de administração.

Entretanto, nasceu um problema sintomático dentro desse contexto, qual seja, a disputa, entre essas entidades, do poder de receber os recursos correspondentes, com prejuízo para todo o sistema. A problemática mitigou-se com o advento da Lei no 5.988/73 que criou para reger o setor o Conselho Nacional de Direito Autoral (C.N.D.A.) e unificou o sistema de percepção através do Escritório Central de Arrecadação e Distribuição (E.C.A.D.).

É fundamental explicitar, ato contínuo, alguns relevantes aspectos do sistema de arrecadação e distribuição da França, do qual o nosso sistema extraiu poderosos subsídios.

\section{I - O SISTEMA FRANCÊS}

$\mathrm{Na}$ França, o sistema de arrecadação e distribuição de direitos autorais torna-se operacional através das associaçōes ou sociedades de titulares.

As principais sociedades francesas de arrecadação são a "Société des auteurs, compositeurs et éditeurs de musique" (S.A.C.E.M.), a "Société des au- 
teurs et compositeurs dramatiques" ("La Dramatique"), a "Société des Gens de lettres" e a "Société pour l'administration du droit de reproduction mécanique des auteurs, compositeurs et editeurs" (S.D.R.M.) $)^{(1)}$.

O sistema brasileiro encontra inspiração, em muitos aspectos, nas entidades supra-indigitadas.

\section{No setor teatral}

A "Société des auteurs et compositeurs dramatiques" (S.A.C.D.), conhecida sob a denominação "La Dramatique", é constituída sob a forma de sociedade civil, regida pelas disposiçōes dos artigos 1832 e seguintes do Código Civil. Seu objeto social compreende:

- a defesa dos direitos dos associados em face dos usuários;

- a gerência dos direitos de representação e de reprodução;

- a administração de fundos de solidariedade e de gratificaçōes de diferentes categorias de associados, de viúvas de titulares, herdeiros ou parentes;

- a defesa de interesses materiais e morais dos membros da Sociedade.

A S.A.C.D. direciona sua atuação no sentido de imprimir a devida disciplina no relacionamento entre autores e empresários teatrais, fixando uma regulamentação profissional.

A pedra basilar é o "contrat d'abonnement", o qual define os elementos de remuneraçāo proporcional devida pelos empresários teatrais, as modalidades de controle das receitas, e prevê até mesmo uma garantia de reembolso, um penhor de valores mobiliários.

O numerário que a entidade S.A.C.D. arrecada em nome do autor é, em regra, proporcional à receita auferida pelo empresário.

O contrato firmado traz prescriçōes próprias à representaçāo de obra certa e determinada, cuja exploração econômica despertou o interesse do empresário, e dispositivos de ordem geral definidores das obrigações deste em face da S.A.C.D.

\section{No setor musical}

A "Société des auteurs, compositeurs et éditeurs de musique" (S.A.C.E.M.) é um organismo criado em 1851 e constituído sob a forma de so-

(1) Alan Le Tarnec, “Manuel de La Propriété Littéraire et Artistique”, pág. 165. 
ciedade civil entre autores, compositores e editores de música. $O$ fato de aderir à S.A.C.E.M. implica, da parte do autor ou do compositor, a transferência, para a entidade, do direito de autorizar ou interditar a execução, ou representação pública da obra desde a sua criação.

Consoante $o$ art. $4^{\circ}$ dos respectivos estatutos, o objeto de sociedade refere-se precipuamente:

- ao exercício e à administração dos direitos relativos à execução pública, à representação pública, ou à representação mecânica e, notadamente, à percepção e à repartição das rendas provenientes do exercício desses direitos.

- à defesa dos interesses materiais e morais de seus membros em vista e dentro do limite do objeto social da entidade.

Há diferenças essenciais entre os contratos firmados entre o autor musical e a S.A.C.E.M. e os havidos entre o autor teatral e a S.A.C.D., diferenças essas decorrentes da natureza das obras executadas e a diversidade das formas de sua utilização.

Diferentemente do que ocorre com as obras teatrais, no campo musical é praticamente impossível a autorização de uso para cada obra e a intervenção do autor é impraticável. Assim, impōe-se, pois, a denominada autorizaçāo geral.

A S.A.C.E.M. apresenta como principais problemas: a determinação dos organizadores de espetáculos, as aplicaçōes marginais do direito de representação, a exatidão dos programas de obras executadas, como também a renumeração proporcional dos autores.

A determinação do preço da autorização conferida à S.A.C.E.M. levanta a questão do poder das sociedades de autores de fixar as condições, destacadamente pecuniárias, de utilização das obras de seus membros.

A remessa, pelos usuários, do programa fiel das execuçôes musicais é uma necessidade imperiosa, porque constitui o documento de base para repartição das rendas entre os titulares das obras executadas. $O$ não envio dos programas acarreta o pagamento de uma pesada multa à entidade. Freqüentemente, os programas são redigidos pelos músicos ou pelos chefes de orquęstra, pessoas de moralidade profissional reconhecida pela S.A.C.E.M.

Um serviço de inspetores cuida da veracidade desses programas e apura eventuais negligências ou fraudes cometidas. 
Há duas grandes formas de repartição de direitos autorais na França, conforme noticia André Schmidt ${ }^{(2)}$ :

- "repartition au programme" - forma mais eqüitativa, porém mais onerosa. É o sistema preferido da S.A.C.E.M. A renda auferida em cada sessão musical é dividida entre as obras executadas, consoante o programa enviado pelo usuário. Esta forma de repartição é aplicada a concertos, turnês, danceterias e, sobretudo, a redes de rádio, televisão e cinema.

Além da onerosidade, outra desvantagem é a eventual adulteração dolosa do programa.

- "repartion par caisse" - a repartição por caixa é menos dispendiosa, contudo não satisfaz a noção de justiça. Consiste em reunir o montante arrecadado proveniente de uma forma de utilização (ex.: "juke-boxes") num fundo comum a fim de ser partilhado com base numa seleção de obras estabelecida pela sociedade segundo os métodos estatísticos diversos. Adota-se um mecanismo de sondagem nos estabelecimentos onde são as obras musicais utilizadas através de aparelhos mecânico-eletrônicos.

$\mathrm{Na}$ Argentina, a S.A.D.A.I.C. ("Sociedade Argentina de Autores y Compositores de Música), constituída pelo Dec. 17.648/68, traz fortes semelhanças funcionais e estruturais com a S.A.C.E.M. ${ }^{(3)}$.

\section{III - O SISTEMA NACIONAL}

\section{No setor teatral}

\subsection{Funcionamento}

Antes de entrar-se na área da arrecadação e distribuição dos direitos autorais decorrentes da utilização de obra teatral, cabe um necessário esclarecimento: obras teatrais não só se relacionam com as obras dramáticas propriamente ditas, destinadas ao palco, ao rádio ou a TV, como abarcam também as obras dramático-musicais, tais como óperas, operetas, patomimas e ballet.

O relacionamento autor teatral-empresário concretiza-se quando se firma o chamado contrato de representação, através do qual o autor confia ao empresário a montagem e a encenação da obra, para sua exploração econômica, mediante a remuneração ajustada, de regra proporcional aos resultados obtidos.

(2) “Les Sociétés D’Auteurs. S.A.C.E.M.-S.A.C.D. Contrats de représentation", pág. 247.

(3) Edwin R. Havey, "Derechos de Autor, de La Cultura y de La Información”, pág. 38. 
Esse relacionamento, porém, é intermediado pela Sociedade Brasileira de Autores Teatrais (S.B.A.T.), na condição de mandatária do autor, com fulcro no art. 104 da Lei no 5.988/73. O representante legal da Sociedade assinará o contrato de representação pelo autor.

É pertinente abrir um parêntese para explicar os principais traços do contrato de representação, cuja regulamentação está fixada entre os arts. 73 e 79 da Lei de Direitos Autorais.

O empresário, por exemplo, não pode comunicar o manuscrito a pessoa estranha ao teatro onde se representa se não tiver licença do autor.

Se o contrato não fixar prazo dentro do qual deva ser representada a peça, o autor poderá intimar o empresário para que o fixe, cominando-lhe como pena a Rescisão do contrato. Evita-se, deste modo, que a exploração econômica da teatral permaneça dentro da órbita do empresário "ad eternum".

Outro dado interessante é a impossibilidade que atinge os credores do empresário de penhorar a parte da renda do espetáculo reservada ao autor para remuneração do seu trabalho.

Outra nota característica no contrato de representaçāo é o fato de o autor de obra dramática não poder fazer alteração na substância de sua obra, sem o consentimento do empresário que a faz representar. Ele pode perfeitamente impor-se perante o autor e impedir que este modifique a peça. Quiçá isto se justifique em razão dos altos custos que tem o empresário com a montagem e encenação de uma peça.

Voltando à assinatura do contrato de representação, a sua conclusão é a parte final de um interessante liame jurídico que se inicia com o ato de filiação do autor à S.B.A.T. através de um instrumento formal. A partir daí a entidade torna-se mandatária do autor, consoante o art. 103 da Lei no 5.988/73. No ato de filiação, procede-se ao registro da obra ou das obras junto à Sociedade.

O empresário, ao se interessar pela utilização de uma obra teatral, procura a S.B.A.T. Esta, por sua vez, formaliza consulta, também através de instrumento, para obter aquiescência do autor. Dada a celeridade do mundo negocial, essa consulta pode se dar inicialmente por via telefônica e depois formalizada. Em geral, o principal ponto da consulta é o montante de direitos autorais a ser pago. Via de regra, o quantum é de $10 \%$ da renda bruta, entendida esta como a receita de ingressos ou subvenção paga ao empresário a qualquer título, descontados os tributos. Todavia, nada impede que o valor seja fixado acima ou abaixo daquele percentual.

Obtida a concordância do autor, aí sim, é assinado o contrato entre o empresário e a S.B.A.T. 
O pagamento dos direitos autorais ao fiscal da S.B.A.T. faz-se na bilheteria do próprio teatro no dia da representação ou no dia seguinte, mediante a apresentação de uma via do "bordereau" de receita devidamente assinado pelo empresário e pelo bilheteiro do teatro. Onde não é possível a presença do fiscal, o pagamento pode ser feito na sede da sucursal ou agência da S.B.A.T. Em determinadas localidades, a arrecadação é efetuada semanalmente.

"No bordereau" estão discriminadas a receita e as despesas de uma ou mais sessões realizadas no dia da representação e a quantia que cabe à S.B.A.T.

Os dados constantes do "bordereau" são lançados na ficha de contabilidade que cada autor teatral tem na sucursal de São Paulo e depois repassados ao computador do escritório central da S.B.A.T., no Rio de Janeiro. A sociedade deposita o numerário na conta-corrente do autor ou aguarda que ele venha buscá-lo.

\subsection{A S.B.A.T.}

A Sociedade Brasileira de Autores Teatrais (S.B.A.T.), fundada em 1917 por três baluartes da cultura nacional no início deste século (Viriato Correa, Raul Pederneiras e Chiquinha Gonzaga), seguiu os moldes da sociedade francesa, criada no século passado, quanto à constituição e funcionamento.

Mesmo com a unificação do sistema de arrecádação e distribuição em torno do E.C.A.D., a S.B.A.T. continuou a recolher separadamente os direitos no setor teatral, através de convênio. A principal justificativa deste tratamento diferenciado baseia-se na auferição peculiar dos rendimentos provenientes da utilização de, obra teatral. $\mathrm{Na}$ área musical, a auferição segue outros parâmetros e encontra muitos obstáculos como se verá em tópico ulterior.

Quanto à estrutura administrativa da S.B.A.T., a matriz está localizada na cidade do Rio de Janeiro. Há sucursais em cada uma das capitais brasileiros e nas cidades do interior do Brasil há agências.

Em termos internacionais, a S.B.A.T. representa em nosso território 18 entidades teatrais estrangeiras, incluindo as Sociedades de Autores da U.R.S.S. e da Tchecoslováquia. Certa vez, nossa jurisprudência foi incitada a se manifestar sobre a utilização da peça de um autor francês em nosso país, não sendo ele devidamente filiado à S.B.A.T. É um típico caso de representação de 2o grau, pois o autor pertence aos quadros da entidade teatral francesa que é representada, pela S.B.A.T., no Brasil. A sociedade brasileira arrecada os devidos direitos autorais e remete-os, via Banco Central, à sociedade francesa que os repassa a seu filiado. 


\section{No setor musical}

\subsection{Funcionamento}

No intróito da análise do sistema arrecadação e distribuição de direitos autorais na área musical, é mister trazer à luz das meditaçōes alguns conceitos fundamentais.

Considera-se usuário de direito autoral toda a pessoa física ou jurídica que utilizar obras musicais, lítero-musicais, fonogramas e videofonogramas, visando a comunicação pública, direta ou indireta, por qualquer meio ou processo, seja a utilizaçăo caracterizada como geradora, transmissora, retransmissora, distribuidora ou redistribuidora. Dois são os tipos de usuário:

- o permanente - aquele que utiliza a obra musical ou lítero-musical um mínimo de 12 vezes por mês, no decorrer de 10 meses por ano num mesmo estabelecimento, do qual seja proprietário ou arrendatário;

- o eventual - aquele que utiliza esporadicamente a obra musical.

E visualizam-se três formas de utilização:

- Execução musical - por qualquer meio ou processo, inclusive pela captação e ampliação da programação recebida em espetáculos musicais (shows), espetáculos circenses, espetáculos carnavalescos, serviços de alto-falante;

- Transmissão ou retransmissão musical - com ou sem imagem, por rádio, televisão ou outros meios de análogos;

- Distribuição e/ou redistribuição musical - com ou sem imagem, pela rede telefônica, sistema satélite, cabo ou outros meios análogos.

O sistema de arrecadação promovido pelo E.C.A.D. biparte-se consoante se trate de utilizações permanentes ou de utilizações eventuais.

Em se tratando de utilizações permanentes, o pagamento dos direitos autorais faz-se mensalmente. Preterindo-se momentaneamente a peculiar situação das emissoras de radiodifusāo e televisão, há duas formas quase sempre alternativas de auferição do montante a ser pago.

- cobrança por participação percentual sobre a renda bruta (variação entre $2,5 \%$ e $7,5 \%)$

- cobrança por parâmetro físico, isto é, com base nas dimensōes do local onde é utilizada a obra musical. Em regra, cobra-se uma quantidade X de BTNs para cada dez metros quadrados do recinto. 
Em certas hipóteses, só se aplica o sistema de cobrança por parâmetro físico. Isto acontece em relação aos terminais, shoppings, condomínios e edifícios.

Em especialíssimos casos, a cobrança por parâmetro físico deixa de lado a tradicional metrificação e adota insólitos referenciais. Assim, uma empresa de transporte aéreo paga um determinado valor em BTN por vôo realizado; uma empresa de transporte marítimo ou fluvial paga por embarcação; uma empresa de transporte ferroviário, por composição; e uma empresa transporte rodoviário paga por veículo.

As emissoras de radiodifusão também pagam mensalmente os direitos autorais, mas o sistema de cobrança adota como referenciais a potência mensurada em Watts ou Kilowatts e o nível populacional da localidade onde a emissora está situada. Desta maneira, por exemplo, uma emissora com 200 Kilowatts de potência situada numa cidade de 500.000 habitantes pagará mais direitos autorais que uma emissora com 100 Kilowatts sediada numa cidade com 100.000 habitantes.

No que tange às estações de TV, há tabelas diferenciadas para emissoras comerciais e não comerciais. A cobrança tem como referencial apenas o nível populacional do lugar onde se encontra instalada a estação. Se a emissora tiver um ou mais estúdios em outros municípios, para efeito de classificação do nível populacional, prevalecerá o município de maior população.

Quanto às utilizações eventuais, a situação é mais simplificada: a cobrança leva em conta o percentual sobre a renda bruta ou o parâmetro físico e dá-se o pagamento a cada espetáculo ou exibição, não sendo, portanto, mensal como ocorre nas utilizaçōes permanentes.

Está aí o sistema de arrecadação. Passemos para o sistema de distribuição.

Os títulos das músicas executadas, os nomes dos respectivos autores e o número de execuções são levantados pelos Serviços de Escuta e por um setor do E.C.A.D. que analisa os programas que lhe são enviados e investiga anúncios promocionais de shows em jornais e periódicos. A prática mostra-nos quão esse controle é repleto de lapsos e fragmentado.

Chega-se ao valor de cada execução dividindo-se o montante total arrecadado ao final do mês pelo número de execuçōes. Em termos exemplificativos se esse montante foi de 1.000 .000 cruzados e o número de execuções chegou a 100.000 , o valor de cada execução é de 10 cruzados.

Mensalmente, o E.C.A.D. encaminha o demonstrativo de cada autor que fez jus ao numerário à sociedade musical à qual está filiado (só pode ele per- 
tencer a uma única entidade representativa, conforme o $\S 1$ o do art. 103 da Lei no 5.988/73). O demonstrativo vai acompanhado de um contra-cheque. A sociedade repassa a seu filiado a quantia a que ele tem direito.

\subsection{O E.C.A.D. e as associações musicais}

O Escritório Central de Arrecadação e Distribuição (E.C.A.D.), colocado em funcionamento no ano de 1977, representa a expressão pragmática do processo de unificação da cobrança dos direitos de execução musical, processo que fora idealizado, em suas linhas gerais, pela Lei no 5.988/73.

A natureza jurídica do E.C.A.D. é marcada por um singular hibridismo, pois, a despeito de ser uma associação de caráter civil, o Estado, através do Conselho Nacional de Direito Autoral, exerce sobre a entidade a tríplice função de normalização, fiscalização e orientação. Nesse passo, é importante aduzir que o Estatuto do E.C.A.D. foi aprovado por ato normativo do C.N.D.A. (Resolução n- 54, de 22.07.87). Sua elaboração obedeceu estritamente outra resolução do Conselho, a de no 46 (de 25.02.87), que delineou os principais aspectos que deveriam ser atendidos.

Também por força de resolução do C.N.D.A., estabeleceu-se como fonte de recursos para a manutenção do Escritório e de suas atividades operacionais um percentual que incide sobre as arrecadações brutas oriundas do resultado da utilização pública, por parte de obras que geram direitos autorais. Quis o legislador determinar a fonte básica, fundamental ou essencial, não se descartando outras fontes como as resultantes da venda de material imprestável e até de um imóvel. Frise-se, porém, o seguinte: as duas funções precípuas do E.C.A.D. são arrecadar bem e distribuir bem. Seus esforços materiais e humanos devem estar canalizados para a consecução desse desiderato. Qualquer fonte paralela de renda que venha a obliterar ou mesmo prejudicar a função do Escritório deve ser rejeitada.

As associaçōes de titulares são as legítimas proprietárias da mesma entidade. O E.C.A.D. não constitui um fim em si mesmo. É um simples meio, porquanto sua finalidade reside na boa prestação de serviços aos titulares, através de sua associação, mesmo que isso importe na elevação do custo operacional do Escritório. É um órgão de gestão coletiva, para fins de arrecadação e distribuição dos direitos patrimoniais de autores, intérpretes, executantes, produtores fonográficos e editores musicais.

A despesa operacional mais preocupante do E.C.A.D., que é a administração e o processamento dos créditos retidos, existe basicamente em função do não-fornecimento de dados cadastrais por parte dos editores e subeditores musicais e de suas associações, que desobedecem, desta forma, os dispositivos estatutários do Escritório. 
Os custos dos direitos autorais para a utilização pública de obras artísticas, musicais, lítero-musicais e de fonogramas, estāo fixados na tabela de preço oficial, organizada pelo E.C.A.D. e homologada pelo C.N.D.A. consoante as disposiçōes legais. Por conseguinte, estão vedados quaisquer acordos entre as partes que venham a descumprir o estipulado na indigitada tabela. Eventuais procedimentos marginais colocariam em serviço a integridade moral da instituição que, em momento nenhum, pode ficar sujeita à vontade subjetiva de seus agentes.

Efetuada a arrecadação, o E.C.A.D. distribui o numerário arrecadado entre as associaçōes representativas dos titulares de direitos autorais, as quais, por sua vez, se encarregam do repasse a seus filiados. Tais entidades dependem de autorização estatal para sua criação e funcionamento e encontram-se sujeitas às normas regulamentadoras expressas entre os cânones 103 e 114 da Lei no $5.988 / 73$.

A despeito de ser a tendência dos membros do C.N.D.A. favorável à unificação dos titulares de direitos da mesma natureza sob os auspícios de uma mesma associação, o Conselho jamais tomou qualquer atitude no sentido de coibir a pluralidade de associaçōes de uma mesma categoria que se verifica há muitos anos em nosso país. A lei autoral tolera a existência de mais de uma associação de titulares congêneres, com base na exegese do $\S 1^{\circ}$ do art. 103.

As Associaçōes, para facilitar o controle que realizam, recebem, por parte do E.C.A.D.:

1. relaçōes de execuçōes pela "Informa Som" em ordem alfabética de músicas e de intérpretes;

2. relaçōes de distribuição de shows, com datas, locais e quantias;

3. relações de distribuição de filmes, com período e quantia.

Através da Resolução no 37 do C.N.D.A., estipulou-se que as associaçōes depositem os créditos de direitos autorais em conta bancária de cada associado, até 72 horas, após o seu envio pelo E.C.A.D. e, na impossibilidade do depósito, a aplicação de tais valores no mercado financeiro e o subseqüente repasse proporcional a cada associado. Procura-se evitar, com esse expediente, a série de abusos em que os créditos autorais de diversos titulares (principalmente os de menor expressāo econômica), sob̉ a estranha alegação de que "nāo eram reclamados ou procurados", serviam tão somente para engrossar as aplicaçōes financeiras de algumas associações.

Essa resolução não exprime um ato tutelar ou intervencionista do Estado sobre as associaçōes de titulares, entidades civis de caráter privado. A ação es- 
tatal, porém, é necessária quando visa a atender o bem comum, como ocorre no caso em tela.

\section{Análise do Anteprojeto de Lei elaborado pelo C.N.D.A.}

O anteprojeto traz mudanças essenciais na atual sistemática do direito autoral como a não atribuição de direitos a pessoas jurídicas, a vedação do contrato de cessão de direitos autorais e a extirpação de regras limitativas de direitos autorais. São inovaçōes que chegam a contrariar princípios basilares sedimentados na jurisprudência alienígena há não pouco tempo e a violar pontos constantes de convençōes internacionais das quais o Brasil é signatário.

Contudo, encontramos um ponto positivo no título VI do Anteprojeto que trata das sociedades de autores e da arrecadação dos direitos decorrentes da utilização de suas obras. $\mathrm{O}$ art. $61 \mathrm{traz}$ a possibilidade de fiscalização dessas sociedades por parte do Ministério Público na forma prevista para as fundaçōes. Talvez seja uma forma de moralizar a atuação das associações de titulares, algumas das quais, como a S.I.C.A.M. (Sociedade de Intérpretes, Compositores e Arranjadores Musicais), abaladas por auditorias promovidas pelo C.N.D.A., mormente agora quando o próprio texto constitucional fortaleceu tais entidades através de expressa representação judicial e extrajudicial de seus filiados. No mais, não há qualquer outra sensível modificação em relação ao atual sistema.

\section{IV - CONCLUSĀO}

A análise dos sistemas de arrecadação e distribuição de direitos autorais atinentes à obra teatral e à obra musical leva-nos a vislumbrar duas realidades distintas ou, até diríamos, opostas. Enquanto na área teatral não apuramos nenhum percalço insusceptível de solução, na área musical os problemas se avolumam de modo desalentador. A visualização de tamanha diferença quiçá se deva ao fato de o sistema nominal de arrecadação atinente às obras teatrais ser muito mais simplificado e eficaz que o sistema genérico e aproximativo das obras musicais.

O método de planilhas e escutas adotado pelo E.C.A.D. na auferição dos rendimentos decorrentes da utilização das obras musicais mostra-se extremamente falho e obsoleto. Verificam-se inúmeras distorçōes, poucos autores recebem muito e muitos recebem nada ou quase nada. Um caso em particular expressa com exatidão essa problemática: um compositor residente no interior do Estado de São Paulo tem muitas de suas obras, executadas nas regiōes Norte e Nordeste do país com grande freqüência, porém, no final do ano de 1988, a associação à qual está filiado remeteu-lhe um cheque de irrisórios quatro cruzados a título de pagamento de direitos autorais. 
$\mathrm{Na}$ França, a computaçāo aperfeiçoou a arrecadação e distribuição de tal maneira que hoje se pode detectar a execução de uma música em qualquer parte do território, com os dados que as singularizam (título completo e nome dos autores). Enquanto a solução tecnológica não chega ao Brasil, o ideal seria aperfeiçoar o sistema de planilhas, impondo sançōes nas esferas administrativas civil e até penal àqueles que fraudam a colheita dos imprescindíveis dados supramencionados.

Outrossim, acreditamos ser urgente uma maior e mais efetiva fiscalização do C.N.D.A. sobre as atividades do E.C.A.D. e das associaçōes de titulares que o compöem. A realidade dos fatos evidencia que tais entidades se enclausuram em verdadeiras redomas, formando feudos onde o espírito corporativo é elevado a níveis censuráveis. A pulverização desses organismos é outro fator prejudicial ao sistema como um todo. A unificação deles em apenas três associaçôes de categoria (uma de direito de autor, outra de direito conexo e outra ainda representativa do produtor fonográfico e o editor de música) não só facilitaria a ação fiscalizadora do Conselho Nacional de Direito Autoral como também propiciaria melhores condiçōes para implementação de nova tecnologia que já existe no sistema francês.

Verdade é que as deficiências de nosso sistema autoral, mormente na área musical, decorrem de um mal crônico constatado no país, qual seja, o descaso à cultura nacional.

São Paulo, dezembro de 1989.

\section{V - BIBLIOGRAFIA}

\section{Obras Nacionais}

- BITTAR, Carlos Alberto - "A Lei de Direitos Autorais na Jurisprudência”, São Paulo, Editora Revista dos Tribunais, 1958.

- "Curso de Direito Autoral", Rio de Janeiro, Editora Forense, 1988.

- "O anteprojeto de lei sobre direitos autorais", in Revista de Informação Legislativa, 102/243.

- "Os Direitos da Personalidade", Rio de Janeiro, Editora Forense Universitária, 1989. 
- CHAVES, Antonio - "Tratado de Direito Civil", Parte Geral I, Tomo I, São Paulo, Editora Revista dos Tribunais, 1984.

- "Direito de Autor I. Princípios Fundamentais", Rio de Janeiro, Editora Forense, 1987.

- MORAES, Walter - "Posição Sistemática do Direito dos Artistas Intérpretes e Executantes", São Paulo, Editora Revista dos Tribunais, 1973.

\section{Obras Estrangeiras}

- GRECO, Paolo e Vercellone, Paolo - “I diritti sulle opere del'ingegno", Torino, Torinense, 1974.

- HARVEY, Edwin R. - "Derechos de Autor, de la Cultura y de La Información”, Buenos Aires, Ediciones Depalma, 1975.

- SCHMIDT, André - "Les Sociétés D’Auteurs. S.A.C.E.M.-S.A.C.D. Contrats de représentation", Paris, Librairie Generale de droit et de jurisprudence, 1971.

- LE TARNEC, Alan - "Manuel de La Propriété Littéraire et Artistique", Paris, Librairie Dalloz, 1966. 